PNL-SA-23899

\title{
RADIOACTIVE EFFLUENT MEASUREMENTS AT THE ARMY PULSE RADIATION FACILITY
}

\section{DISCLAIMER}

R. I. Scherpelz

J. A. Glissmeyer

November 1994
This report was prepared as an account of work sponsored by an agency of the United States Government. Neither the United States Government nor any agency thereof, nor any of their employees, makes any warranty, express or implied, or assumes any legal liability or responsibility for the accuracy, completeness, or usefulness of any information, apparatus, product, or process disclosed, or represents that its use would not infringe privately owned rights. Reference herein to any specific commercial product, process, or service by trade name, trademark, manufacturer, or otherwise does not necessarily constitute or imply its endorsement, recommendation, or favoring by the United States Government or any agency thereof. The views and opinions of authors expressed herein do not necessarily state or reflect those of the United States Government or any agency thereof.

Presented at the

Topical Meeting on Physics, Safety \& Applications

of Pulse Reactors

November 13-17, 1994

Washington, D.C.

Prepared for

the U.S. Department of Energy

under Contract DE-AC06-76RLO 1830

Pacific Northwest Laboratory

Richland, Washington 99352 


\section{DISCLAIMER}

Portions of this document may be illegible in electronic image products. Images are produced from the best available original document. 


\section{RADIOACTIVE EFFLUENT MEASUREMENTS AT THE ARMY PULSE RADIATION FACILITY}

\author{
Robert I. Scherpelz \\ Pacific Northwest Laboratory \\ P.O. Box 999 \\ Richland, Washington 99352
}

\author{
John A. Glissmeyer \\ Pacific Northwest Laboratory \\ P.O. Box 999 \\ Richland, WA 99352
}

\section{ABSTRACT}

Staff from the Pacific Northwest Laboratory (PNL) performed measurements of the radioactive effluents emitted by the Army Pulse Radiation Facility (APRF). These measurements were performed by collecting the cooling air that passed by the APRF reactor as it operated, passing the air through filters to collect the particulates and iodines, and collecting samples of the air to be analyzed for noble gases.

The reactor operated for four test runs, including two pulses and two steady state runs. After each reactor run, the filters were counted using gamma spectrometry to identify the nuclides and to determine the activity of nuclides deposited on the filters.

The study provided radionuclide release fraction data that can be used to estimate the airborne emissions resulting from APRF operations. The release fraction for particulate fission products and radioiodines, as derived from these mesurements, was found to be.8.9 $\times 10^{-6}$ for reactor pulses and $4.3 \times 10^{-6}$ for steady state operation. These values compare to a theoretical value of $1.5 \times 10^{-5}$.

\section{INTRODUCTION}

The Army Pulse Radiation Facility (APRF) is a fast burst reactor located on the Aberdeen Proving Grounds in Maryland. ${ }^{1}$ The reactor can operate in either a pulsed mode or a steady state mode, and it can operate either inside the reactor building or outdoors. Concern has been expressed recently over the emission of airborne radionuclides that are produced during reactor operation and could potentially be transported downwind to expose offsite populations. In order to quantify the potential for these emissions, staff from the Pacific Northwest Laboratory (PNL) performed a set of measurements to determine the quantity of radionuclides emitted during reactor operation.

The measurements were performed by collecting the cooling air that passed by the APRF reactor as it operated, passing the air through filters to collect the particulates and radioiodines, and collecting samples of the air to be analyzed for the presence of radioactive noble gases. Gamma spectrometry was used to analyze the exposed filters; samples of the filters were sent to an analytical laboratory for radiochemical analysis to identify beta and gamma emitters; and the collected air samples were sent to an analytical laboratory for a cryogenic analysis to measure the presence of noble gases.

The reactor was operated in two different pulsed runs to establish counting backgrounds. The reactor was then run in two pulses and two steady state runs to collect data for actual analysis. The set of test runs presents a range of operating conditions that are representative of the conditions expected during the normal operations of the APRF reactor.

\section{SAMPLING SYSTEM}

The APRF reactor core is gas cooled using either compressed air or vapor from liquid nitrogen. The cooling gas flows through the core and escapes through channels at the bottom of the core's shroud. To capture the entire effluent from the reactor, the bottom end of the shroud was lowered into the open end of the sample collection apparatus intake pipe, shown in Figure 1. The sampling system maintained an intake airflow exceeding that of the reactor cooling gas by means of a fan, ensuring that all of the cooling gas was swept into the intake pipe.

Three types of samples were collected for each test: particles, iodine and other gases that would adsorb on activated carbon, and noble 
gases. Because it was desired to collect particle and iodine samples from the entire reactor cooling air stream, unusually large collection devices were employed. Particles were collected with a 2 -ft $\times 2$-ft wide by 11.5 -in. deep HEPA filter. Iodine and other adsorbable gases were collected with a $2-\mathrm{ft} \times 2-\mathrm{ft}$ wide by 16-in. deep activated carbon filter. Samples for noble gas analysis were collected by drawing a small subsample air flow from the exhaust air stream and collecting it in special low adsorption plastic bags.

The apparatus air flow and temperature were regulated by controlling the speed of the fan motor. The air flow was adjusted to ensure that the safe operating temperature $\left(49^{\circ} \mathrm{C}\right)$ for the filters would not be exceeded. To minimize the effects of long term neutron activation contamination of the components, aluminum was used as much as possible in the fabrication of the apparatus, and wood frame HEPA filters and charcoal filters were used.

\section{REACTOR TEST RUNS}

Seven tests were conducted, including three background runs, two test pulses and two test steady state runs. The four test runs represented the expected range of operating conditions for the reactor, and would provide emission data bracketing all operating conditions.

The first test pulse was rated at $24.6 \mathrm{~kW}$ min, resulting in $4.35 \times 10^{16}$ fissions. The peak fuel temperature, which occurs near the center of the core, was 161 degrees $C$. The peak-to-average temperature ratio is about two. This first test pulse is a relatively low-level pulse for the APRF reactor. The second pulse was a high-level pulse that produced $1.01 \times 10^{17}$ fissions, and was rated at $58.9 \mathrm{~kW}$-min. The peak fuel temperature for the second pulse was 335.7 degrees $\mathbf{C}$.

The first steady state run had a nominal power level that was comparable to the first test pulse, with $24.9 \mathrm{~kW}$-min. A total of $4.4 \times 10^{16}$ fissions were produced. The reactor operated for 6.15 minutes and the maximum in-core fuel temperature was 112 degrees $C$. The second steady state run had a nominal fission output that - was approximately comparable to ten times the second pulse, with $559 \mathrm{~kW}$-min. A total of
$9.93 \times 10^{17}$ fissions were produced. The reactor operated for 81 minutes during this run, and the maximum fuel temperature at the time of shutdown was 333 degrees C: $^{-}$

Following each reactor test run, the sampling system remained undisturbed for a period of approximately an hour while the radiation levels in the reactor building decreased. When staff could enter the reactor building, the HEPA and charcoal filters were removed from the sampling system and carried to a separate room for on-site non-destructive analysis using gamma spectrometry. After the on-site analysis, the HEPA filters were partly disassembled and portions removed for further analysis off-site. The noble gas samples were transferred from the sample plastic bags and compressed into gas cylinders for off-site analysis.

\section{GAMMA SPECTRAL MEASUREMENTS}

Radionuclides that were collected by the HEPA and carbon filters were measured by gamma spectrometry. This technique used a high purity germanium (HPGe) detector for measuring the gammas emitted by radionuclides deposited on the filter. Each collected gamma spectrum contained a number of lines or peaks that corresponded to characteristic gammas emitted by the radionuclides. Thus an analysis of the spectrum provided an identification of the gammas collected on the filter and, by using appropriate detector efficiency values, quantified the activity of these nuclides at the measurement time.

Prior to the measurements, the HPGe detectors were calibrated by counting check sources positioned on the front and back faces of HEPA and carbon filters. The filters were positioned 48-in. from the face of the detector, matching the counting positions for the APRF tests. Since the photon emission rates of the calibration sources were known, the count rate for each gamma energy could be converted to nuclide activities on the filters for the counting configurations encountered at APRF. Performing calibration measurements with check sources on both the front face and back face of each filter accounted for deposition within the filter and attenuation of emitted photons by filter media. 
Several types of background counts were performed in the truck lock of the APRF facility, which was used as the gamma counting room. These counts accounted for room background and for gamma peaks that may occur on a filter that are not directly attributable to radionuclide emission by the reactor during a reactor run. The results of these measurements were used to correct each of the gamma counts from the test runs.

Following each reactor test run, the HEPA and carbon filters were carried to the truck lock and set up in two established counting positions, with one HPGe detector positioned 48 inches from the HEPA filter and another HPGe set up 48-in from the carbon filter. The two filters were positioned far from each other to minimize interfering signals at the detectors. Within one or two hours after irradiation, a count was made with the inlet side of each filter facing the appropriate detector, and then another count was made with the outlet side facing the detector. After an additional decay time of about 24 hours, the inlet and outlet side of the HEPA filters were again counted to take advantage of radioactive decay in identifying the nuclides.

Following the counts, each recorded gamma spectrum was analyzed to identify the gamma peaks, subtract background, and find the net count rate for each peak. Corresponding radionuclides were identified, and detector efficiencies were used along with the gamma yield for each nuclide to determine the radionuclide loading of the filter. The nuclide activities were then backward-decayed to determine the activities at the end of irradiation. All of the gamma spectra from each reactor test run were similarly analyzed and the results averaged to determine a representative end-of-irradiation filter loading for each detectable radionuclide.

Table 1 presents the results of the gamma measurements and subsequent analysis. The radionuclide quantities are the activities released by the reactor, normalized to the $\mathrm{kW}$-min of reactor operation for the given test run.

\section{RELEASE FRACTION}

The data presented in Table 1 could be used to derive a release fraction for reactor operation. The release fraction is defined as the quantity of radionuclides released by the reactor's operation divided by the quantity of radionuclides that are created by that operation. The quantity produced is determined theoretically, using the ORIGEN2 computer code. ${ }^{2}$

A study was performed using the ORIGEN2 computer code for a base case of reactor steady-state operation totaling 950 $\mathrm{kW}$-min. The calculated activity of each radionuclide at the conclusion of the operation was normalized to one $\mathrm{kW}$-min so it could be used as the denominator of the release fraction.

The measured activity for each nuclide was used as the numerator of the release fraction. For each nuclide, one release fraction was determined for steady state operation and another for pulsed operation. The release fractions for pulses ranged from $3.7 \times 10^{-6}$ to $3.0 \times 10^{-5}$, with an average of $8.9 \times 10^{-6}$. For steady state operation, the release fractions ranged from $2.2 \times 10^{-6}$ to $8.5 \times 10^{-6}$, with an average of $4.3 \times 10^{-6}$. These release fractions are applicable to iodines and particulate fission products.

A theoretical release fraction had been derived for radionuclides produced in the APRF reactor. The theoretical release fraction was based primarily on geometrical considerations, assuming that radionuclides would only be emitted from the core if they were produced by a fission reaction near a core surface, and produced with enough kinetic energy to be ejected from the surface. Based on these considerations, a theoretical release fraction for particulate fission products and iodines was estimated to be $1.5 \times 10^{-5}$. The averaged values determined by these measurement fractions are smaller than the theoretical value.

\section{CONCLUSIONS}

This study was subject to a number of uncertainties that typically accompany radiation measurements. There is also some uncertainty in the assumption that $100 \%$ of the particles emitted by the reactor were trapped on the filters. The overall uncertainty in the study is illustrated by the range of values found in the release fractions. Although the measured ranges may appear large, however, the size of the overall uncertainty is 
consistent with the nature of the problem being investigated and the methods of analysis available.

The gamma measurements showed excellent internal consistency, with multiple gamma peaks for a given nuclide present in the expected relative sizes for confirmation of nuclide identification. Performing several counts at different times after irradiation also gave good confirmation of nuclide identification by observing half-life effects.

The release fractions determined by this study are "in the same ballpark" as the theoretical release fraction, but somewhat lower. These values thus give a sound experimental basis for estimating the release of radionuclides from the operation of the APRF reactor.

\section{ACKNOWLEDGEMENTS}

This work has been supported by the U.S. Army under a Related Services Agreement with the U.S. Department of Energy. Pacific Northwest Laboratory is operated for the U.S. Department of Energy by Battelle Memorial Institute under contract DE-AC06-76RLO 1830. Particular thanks are given for the help and support given by members of the U.S. Army's Combat Systems Test Activity organization, including Dr. A. H. Kazi, Mr. Denver Miser, and Mr. Larry Davis.

\section{REFERENCE}

1. A. H. Kazi and R.I. Scherpelz, "Radionuclide Source Term for Environmental Monitoring and Assessment of a Fast Burst Reactor," Proceedings of the ANS Topical Meeting on the Physics, Safety, and Applications of Pulse Reactors, Washington, D.C., November 13-17, 1994. (These Proceedings)

2. A.G. Groff, A User's Manual for the ORIGEN2 Computer Code. ORNL/TM-7175, Oak Ridge National Laboratory, Oak Ridge, Tennessee (1980). 


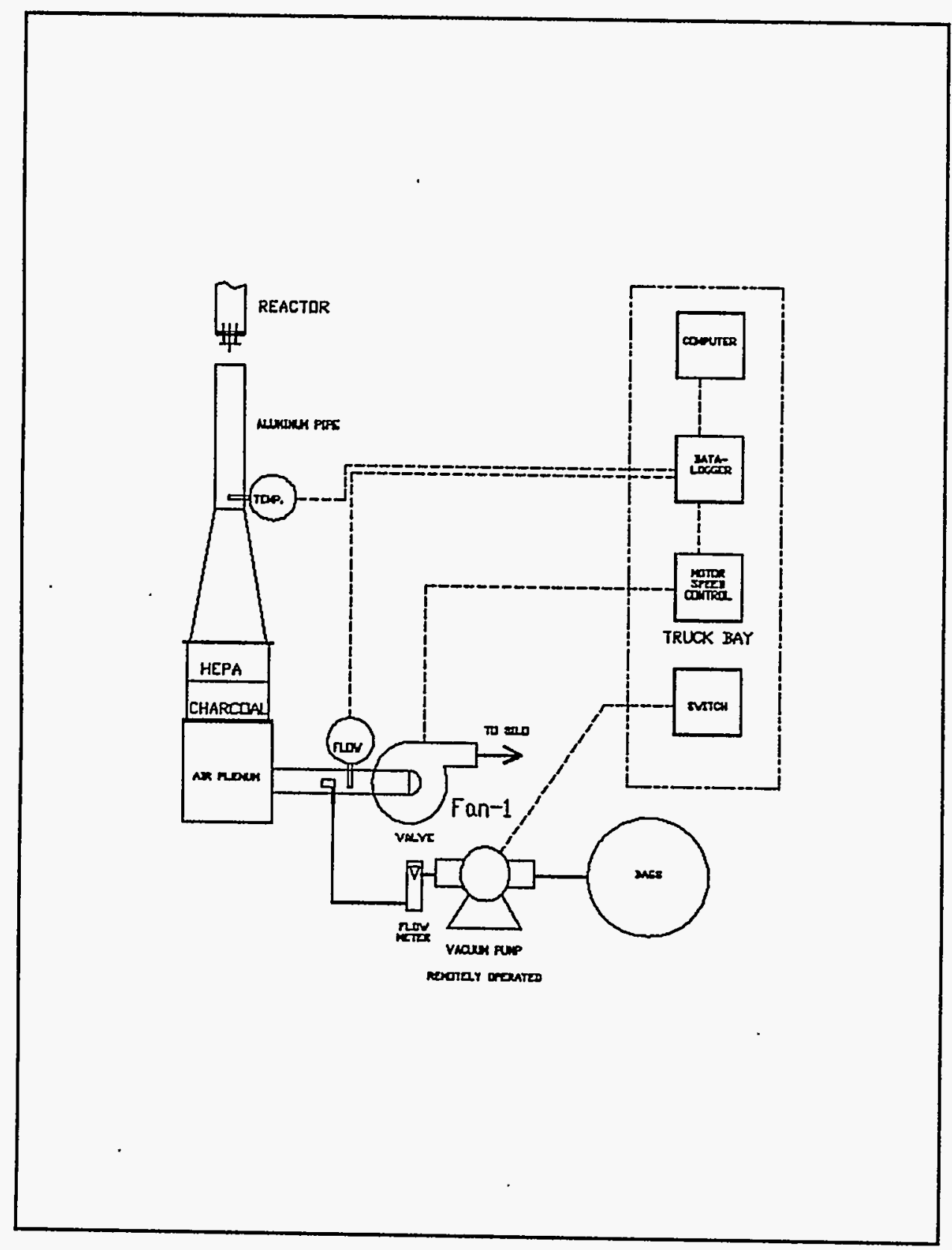

FIGURE 1. Sampling Apparatus Schematic 
Table 1. Measured radionuclide activities from the APRF reactor runs,

\begin{tabular}{|c|c|c|c|c|c|}
\hline Radiouclide & Half Life (h) & $\begin{array}{l}\text { Pulse } 1 \\
(\mu \mathrm{Ci} / \mathrm{kW}-\mathrm{min})\end{array}$ & $\begin{array}{l}\text { Pulse } 2 \\
(\mu \mathrm{Ci} / \mathrm{kW} \text {-min })\end{array}$ & $\begin{array}{l}\text { St. State } 1 \\
(\mu \mathrm{Ci} / \mathrm{kW}-\mathrm{min})\end{array}$ & $\begin{array}{l}\text { St. State } 2 \\
(\mu \mathrm{Ci} / \mathrm{kW}-\mathrm{min})\end{array}$ \\
\hline${ }^{131} I$ & 193 & .0084 & .0115 & & .0042 \\
\hline${ }^{132} I$ & 2.3 & & .0088 & & .0250 \\
\hline${ }^{133} \mathrm{I}$ & 20.8 & .130 & .166 & .0502 & .101 \\
\hline${ }^{134} \mathrm{I}$ & .877 & 3.71 & 5.06 & 2.37 & 2.39 \\
\hline${ }^{135} \mathrm{I}$ & 6.60 & .250 & .440 & .0872 & .377 \\
\hline${ }^{82} \mathrm{Br}$ & 35.3 & .0814 & .120 & .118 & .0978 \\
\hline${ }^{91} \mathrm{Sr}$ & 9.5 & .250 & .282 & .133 & .104 \\
\hline${ }^{91 \mathrm{~m}} \mathrm{Y}$ & .8285 & .0573 & & & \\
\hline${ }^{92} \mathrm{Sr}$ & 2.71 & 1.26 & 1.49 & .575 & .713 \\
\hline${ }^{92} \mathrm{Y}$ & 3.54 & 1.43 & .712 & & .338 \\
\hline${ }^{93} \mathrm{Y}$ & 10.1 & .365 & .364 & & .196 \\
\hline${ }^{97} \mathrm{Zr}$ & 16.9 & & & & .123 \\
\hline${ }^{97} \mathrm{~m} / \mathrm{b}$ & .015 & & .535 & .0528 & .186 \\
\hline${ }^{97} \mathrm{Nb}$ & 1.23 & .0905 & .132 & .0456 & .0796 \\
\hline${ }^{99} \mathrm{~m}_{\mathrm{Tc}}$ & 6.02 & .549 & .482 & .365 & .0096 \\
\hline${ }^{101} \mathrm{Mo}$ & .2433 & 14.6 & 15.1 & & \\
\hline${ }^{101} \mathrm{Tc}$ & .2367 & 16.5 & 43.5 & 148 & 17.0 \\
\hline${ }^{103} \mathrm{Ru}$ & 944.4 & & .0038 & & \\
\hline${ }^{105} \mathrm{Ru}$ & 4.44 & .178 & .185 & & .0882 \\
\hline${ }^{129} \mathrm{Sb}$ & 4.40 & .063 & .121 & & .0519 \\
\hline${ }^{138} \mathrm{Cs}$ & .537 & 1.11 & 1.31 & & \\
\hline${ }^{139} \mathrm{Ba}$ & 1.385 & 1.27 & .749 & .605 & .466 \\
\hline${ }^{141} \mathrm{Ba}$ & .3045 & 10.6 & 8.15 & 2.85 & 1.93 \\
\hline${ }^{141} \mathrm{Ce}$ & 780 & & .0072 & & .0017 \\
\hline${ }^{142} \mathrm{La}$ & 1.59 & 1.86 & 1.56 & .804 & .665 \\
\hline${ }^{143} \mathrm{Ce}$ & 33 & .0651 & .0788 & .0358 & .0431 \\
\hline
\end{tabular}

